\title{
The usefulness of traditional birth attendants to women living with HIV in resource-poor settings: the case of Mfuwe, Zambia
}

\author{
Choolwe Muzyamba ${ }^{1,2^{*}}$, Wim Groot ${ }^{3,4}$, Sonila M. Tomini ${ }^{1,5}$ and Milena Pavlova ${ }^{3}$
}

\begin{abstract}
Background: Although there is increased attention on the role of trained traditional birth attendants (TBAs) in maternal care, most of the research has mainly focused on providing evidence of the relevance of trained TBAs to women in general without a specific focus on women who are HIV positive, despite them being most vulnerable. Therefore, the aim of this study is to fill this gap by assessing the relevance of trained TBAs to women living with HIV in resource-poor settings by using Zambia as a case study.

Methods: Our data collection consisted of two focus group discussions, one involving HIV-positive women utilizing trained TBAs and the other with women not utilizing TBAs. Additionally, in-depth interviews were conducted with trained TBAs and health workers. Thematic analysis was used to analyze the data.

Results: In general, women living with HIV positively characterized the services of TBAs. In the face of an inefficient health system, trained TBAs were seen to be useful in providing efficient, cheap and quality care, counseling, and referral and logistical support, including treatment adherence support.

Conclusion: In Zambia, trained TBAs and professional care are not mutually exclusive but complementary. There is no doubt that HIV-positive women need professionals to handle complications and offer antiretroviral treatment to ensure prevention of mother to child transmission (PMTCT). However, additional "soft" services offered by trained TBAs are equally important in the promotion of maternal health care among HIV-positive women. Thus, it seems there is more to gain by systematically allowing trained TBAs to work alongside professionals in a well-coordinated and complementary manner.
\end{abstract}

Keywords: Maternal health, Traditional birth attendants (TBAs), HIV/aids

\section{Background}

In sub-Saharan Africa, questions of who should assist during childbirth as well as where and under what circumstances childbirth should take place have long been debated [1]. Central to this debate is the role that trained traditional birth attendants (TBAs) should and could play during this process. The World Health Organization (WHO) defines trained TBAs as individuals within the

\footnotetext{
* Correspondence: muzyamba@merit.unu.edu

${ }^{1}$ Maastricht Graduate School of Governance/UNU-Merit, Maastricht University, Maastricht, the Netherlands

${ }^{2}$ A9 Marshlands Village, P.O. Box 32379, Lusaka, Zambia

Full list of author information is available at the end of the article
}

community who assist mothers in maternal care and have learned their skills through apprenticeship which mostly involves informal training on how to take care of pregnant women, conduct deliveries, and provide postnatal services $[2,3]$. Trained TBAs are distinguished from other TBAs who never received any training.

Scholars remain divided on the usefulness of trained TBAs especially for women with HIV who have extra needs (antiretroviral treatment to ensure prevention of mother to child transmission-PMTCT). On one hand, there is a strand of scholars [4] who argue that trained TBAs lack the necessary knowledge and skills to promote maternal health in women with HIV. Consequently, this 
narrative by TBA opponents has dominated the maternal health discourse in countries like Zambia as epitomized by the transposition of this policy into national maternal health policy (which emphasizes institutional delivery) $[5,6]$.

On the other hand, another strand of scholars $[7,8]$ believes that trained TBAs are indispensable in resource-poor settings like Zambia, especially considering the fact that in such areas, health facilities are remotely located, poorly staffed, poorly equipped, overcrowded, and inaccessible. This makes trained TBAs the only feasible, practical, and accessible source of maternal health care. Some scholars emphasize this point by suggesting that any attempt to abandon trained TBAs in resource-poor settings creates a danger of wiping out the only available source of care [7-9]. However, questions on whether trained TBAs can be relevant to women living with HIV in resource-poor settings remain unanswered. Therefore, the aim of this study is to help fill this gap by assessing the relevance of trained TBAs to women living with HIV in resource-poor settings by using Mfuwe, Zambia as a case study.

\section{Methods}

We locate our assessment with the help of the framework of public value in health care provision [10]. The public value framework to health care emphasizes that the relevance of a health care service is seen from its localized interpretation and context-specific responsiveness to local needs [11]. The framework broadly allows local people to characterize a service as relevant or not by relying on their own interpretation of its value given their local needs. The localized interpretation is usually assessed in terms of quality, access, efficiency, and costs of the service. We thus use the public value framework as a heuristics device guiding our analysis and presentation of results.

\section{Ethical clearance}

We obtained ethical clearance from the National Health Research Authority of Zambia and from the Zambian ERES Converge IRB. Other than that, informed consent was sought from the participants before participation. Further, participants were informed of their right to discontinue their participation at any point should they wish to do so.

\section{Study site}

Mfuwe is one of the rural settlements situated in the South Luangwa national park in the Eastern province of Zambia. The main health center in Mfuwe is called "Kamoto Hospital". This hospital caters for a population of over 207,000 people spread roughly over an area of $370 \mathrm{~km}^{2}$ [12, 13]. According to the 2013-2014 Zambia
Demographic Health Survey (ZDHS), it is estimated that over $70 \%$ of the people in Mfuwe live in abject poverty. The HIV prevalence rate in this area ranges from 10.6 to $14 \%$, whereas the maternal mortality rate (MMR) stands at 398 deaths per 100,000 live births [13].

\section{Sampling}

In recruiting our participants, we relied on convenient and purposive sampling techniques. In total, we recruited 40 participants. In order to increase the diversity of our responses, participants were divided into four groups: (a) HIV-positive women who used trained TBAs ( $n=12)$, (b) HIV-positive women who never used trained TBAs $(n=11)$, (c) trained TBAs $(n=8)$, and (d) health workers $(n=9)$. In general, our participants varied in age, educational level, marital status, and occupation. We ensured variety in participants in order to increase the diversity of opinions expressed.

\section{Interviews and focus group discussions}

Focus group discussions (FGDs) were conducted separately with groups A (TBA utilizers) and B (non-TBA utilizers). Further, we conducted individual interviews separately with groups C (trained TBAs) and group D (health workers).

FGDs lasted for an average of $90 \mathrm{~min}$ while interviews lasted for $40 \mathrm{~min}$. All interviews and FGDs were conducted by the first author, a Zambian national, in Chichewa (the local language) and English where possible. A topic guide was used during the FGDs and interviews. The guide included about 11 broad questions ranging from reasons why participants chose to use or not use trained TBAs, women's experiences with the given service (TBAs or professionals) during pregnancy, childbirth, and postpartum. Other questions centered on women's thoughts regarding benefits and disadvantages of the type of service used etc. The topic guide used to interview trained TBAs and professional health workers broadly consisted of questions asking them to describe what services they offered, reasons why those services were offered, experiences encountered during service provision etc. During both FGDs and interviews, we ensured that follow-up questions were asked for clarification and also to encourage respondents to expand upon their answers. The participants in the FGDs came from different ethnic groups but they all spoke the common language of Chichewa and basic English. Interviews were conducted in Chichewa, and where possible, English was used. Participants were also encouraged to express themselves freely in their ethnic dialect. We also made sure that any ethnic words and phrases used that had no English translation or good English equivalent were left un-translated. 


\section{Analysis}

We used NVivo as a software tool to conduct a thematic analysis. Thematic analysis was chosen because it effectively allows the researcher to neatly pinpoint, examine, and describe phenomenon by using themes which systematically elucidate the content of and give meaning to the data [14]. Resulting codes were progressively clustered in 34 number of organizing themes and 17 global themes (see column 1-3 in Table 2).

\section{Results}

Table 1 summarizes key baseline demographic features of our participants. As can be seen, our participants varied in social demographic characteristics. For example, the age ranged from 18 to 63 years with the majority of them being in their twenties and thirties. In terms of educational attainment, the range was from "no education at all" to "university graduates." A substantial number of them had acquired primary education. The number of married and unmarried women was comparable. Similarly, the number of women in employment was somewhat comparable to that of the unemployed.

Table 2 summarizes key findings from our study. A thorough explanation of these findings is given below.

\section{Women who accessed services of trained TBAs}

Although the experience with trained TBAs varied among these women, we observed no major differences in opinions on the basis of age, marital status, and education level. In general, the majority of the women in this group described several benefits of using trained TBAs over facilities, and in the process also noted the shortcomings of using trained TBAs.

In summing up benefits of using trained TBAs, these women pointed out that trained TBAs were easily accessible, cheaper than institutional care, provided efficient and quality care, provided support which included referrals and transportation to facilities, and treatment adherence support.

TBAs were also praised for effectively confronting barriers (such as stigma and discrimination) to better health outcomes in women with HIV. These women argued that this particular action from trained TBAs was especially important because their HIV status made them susceptible to stigma and discrimination in their communities. Almost half of the participants from this group intimated that trained TBAs were involved in advocacy work to challenge stigma, discrimination, and patriarchy. In the words of one of the participants:

"There is still this stigma that is very bad and can cause so much pain. But you see, TBAs have been going round the villages raising awareness about HIV and how stigma and discrimination is not good especially for us HIV positive pregnant women"
Table 1 Participants' demographics

\begin{tabular}{lllll}
\hline ID & Age & Education level & Employment status & Marital status \\
\multicolumn{4}{c}{ Women who had accessed services of trained TBAs during their maternity } \\
1 & 25 & Secondary education & Employed & Widowed \\
2 & 23 & Primary education & Unemployed & Married \\
3 & 41 & No education & Employed & Divorced \\
4 & 33 & No education & unemployed & Married \\
5 & 19 & Vocational education & Employed & Married \\
6 & 33 & Primary education & Employed & Widowed \\
7 & 26 & No education & Employed & Not married \\
8 & 20 & Primary education & Unemployed & Not married \\
9 & 22 & Secondary education & Employed & Married \\
10 & 26 & Primary education & Unemployed & Married \\
11 & 40 & No education & Unemployed & Married \\
12 & 38 & Secondary education & Unemployed & Married
\end{tabular}

Women who had never accessed services of trained TBAs during their maternity

$\begin{array}{lllll}13 & 27 & \text { Secondary education } & \text { Employed } & \text { Married } \\ 14 & 24 & \text { Vocational training } & \text { Unemployed } & \text { Married } \\ 15 & 18 & \text { Secondary education } & \text { Unemployed } & \text { Married } \\ 16 & 34 & \text { Primary education } & \text { Unemployed } & \text { Married } \\ 17 & 40 & \text { No education } & \text { Employed } & \text { Widowed } \\ 18 & 30 & \text { Vocational training } & \text { Unemployed } & \text { Married } \\ 19 & 27 & \text { No education } & \text { Unemployed } & \text { Not married } \\ 20 & 23 & \text { Primary education } & \text { Employed } & \text { Not married } \\ 21 & 22 & \text { Secondary education } & \text { Employed } & \text { Widowed } \\ 22 & 29 & \text { No education } & \text { Unemployed } & \text { Not married } \\ 23 & 33 & \text { Secondary education } & \text { Employed } & \text { Married } \\ & \text { AGE } & \text { Education level } & \text { Years of practice } & \end{array}$

Trained traditional birth attendant

$\begin{array}{llll}24 & 46 & \text { Vocational training } & 22 \\ 25 & 56 & \text { Vocational training } & 19 \\ 26 & 48 & \text { Vocational training } & 18 \\ 27 & 39 & \text { Vocational training } & 11 \\ 28 & 57 & \text { Vocational training } & 26 \\ 29 & 53 & \text { Vocational training } & 20 \\ 30 & 63 & \text { Secondary education } & 30 \\ 31 & 55 & \text { Vocational training } & 27 \\ 32 & 36 & \text { Vocational training } & 4 \\ \text { Medical professionals } & \\ 33 & 48 & \text { University education } & 20 \\ 34 & 60 & \text { University education } & 33 \\ 35 & 57 & \text { University education } & 30 \\ 36 & 46 & \text { University education } & 17 \\ 37 & 53 & \text { University education } & 24 \\ 38 & 33 & \text { University education } & 7 \\ 39 & 26 & \text { University education } & 3 \\ 40 & 28 & \text { University education } & 4\end{array}$


Table 2 Summary of qualitative results

\begin{tabular}{|c|c|c|c|}
\hline Respondent group & $\begin{array}{l}\text { Global } \\
\text { theme }\end{array}$ & Organizing theme & Basic findings from the FGDs and interviews \\
\hline \multirow{9}{*}{$\begin{array}{l}\text { Characterization of TBAs by HIV+ women } \\
\text { who had accessed trained TBAs }\end{array}$} & \multirow{3}{*}{$\begin{array}{l}\text { Quality of } \\
\text { care }\end{array}$} & \multirow[t]{2}{*}{ Quality of care } & -TBAs provide personalized care \\
\hline & & & $\begin{array}{l}\text {-TBAs provide continuous care from antenatal, labor, and } \\
\text { postnatal } \\
\text {-TBAs help in promoting adherence to treatment } \\
\text {-Provided supportive logistic and services }\end{array}$ \\
\hline & & Limitations in quality & $\begin{array}{l}\text { - Lack of skills to handle complications } \\
\text {-Lack of medical supplies and equipment to prevent mother to } \\
\text { child transmission }\end{array}$ \\
\hline & \multirow[t]{2}{*}{ Efficiency } & Efficiency & $\begin{array}{l}\text {-Provided psychological, emotional, and economic support } \\
\text {-Referred and facilitated transportation to facilities } \\
\text {-TBAs work to end stigma, discrimination, and patriarchy through } \\
\text { advocacy } \\
\text { Using advocacy to challenge structural drivers to poor maternal } \\
\text { health outcomes e.g., stigma, discrimination, and patriarchy }\end{array}$ \\
\hline & & $\begin{array}{l}\text { Limitations in } \\
\text { efficiency }\end{array}$ & -Lack of advanced medical equipment and supplies \\
\hline & \multirow[t]{2}{*}{ Affordability } & Affordability & $\begin{array}{l}\text {-Were cheaper and in some cases free } \\
\text {-Payment or token of appreciation was not mandatory }\end{array}$ \\
\hline & & $\begin{array}{l}\text { Limitations in } \\
\text { affordability }\end{array}$ & $\cdot N / A$ \\
\hline & \multirow[t]{2}{*}{ Access } & Access & $\begin{array}{l}\text {-Easily accessible } \\
\text { - Lives within the community } \\
\text {-Always available to provide care from antenatal to postnatal }\end{array}$ \\
\hline & & Limitations to access & $\cdot N / A$ \\
\hline \multirow[t]{9}{*}{$\begin{array}{l}\text { Characterization of TBAs by HIV+ women } \\
\text { who had never accessed trained TBAs }\end{array}$} & \multirow[t]{3}{*}{$\begin{array}{l}\text { Quality of } \\
\text { care }\end{array}$} & \multirow[t]{2}{*}{ Quality of care } & $\begin{array}{l}\text { - Less verbally and physically abusive than professionals in facilities } \\
\text {-Provision of personalized care }\end{array}$ \\
\hline & & & $\begin{array}{l}\text {-More guaranteed support from antenatal until postpartum } \\
\text { - Do provide resources and food } \\
\text {-More friendly and caring than facility-based care }\end{array}$ \\
\hline & & Limitations in quality & $\begin{array}{l}\text {-Professionals have more knowledge and skills to handle } \\
\text { complications than trained TBAs } \\
\text {-Professionals have access to equipment and medical supplies that } \\
\text { can deal with HIV vulnerability during pregnancy but TBAs do not }\end{array}$ \\
\hline & \multirow[t]{2}{*}{ Efficiency } & Efficiency & $\cdot N / A$ \\
\hline & & $\begin{array}{l}\text { Limitations in } \\
\text { efficiency }\end{array}$ & $\begin{array}{l}\text {-TBAs cannot help in PMTCT } \\
\text {-TBAs cannot help easily conduct HIV tests } \\
\text {-TBAs cannot help in the provision of ARVs } \\
\text {-TBAs cannot help in conducting cesarean births }\end{array}$ \\
\hline & \multirow[t]{2}{*}{ Affordability } & Affordability & $\begin{array}{l}\text {-TBAs are cheaper than institutions where they require women to } \\
\text { pay clinical fees } \\
\text {-TBAs are cheaper as they do not require the patient to buy her } \\
\text { own bucket, delivery bags }\end{array}$ \\
\hline & & $\begin{array}{l}\text { Limitations in } \\
\text { affordability }\end{array}$ & $\cdot N / A$ \\
\hline & \multirow[t]{2}{*}{ Access } & Access & $\begin{array}{l}\text {-Always available when called upon } \\
\text {-Follow the patients to their home }\end{array}$ \\
\hline & & Limitations to access & $\cdot N / A$ \\
\hline \multirow[t]{3}{*}{$\begin{array}{l}\text { Characterization of trained TBAs by } \\
\text { trained TBAs }\end{array}$} & \multirow[t]{2}{*}{$\begin{array}{l}\text { Quality of } \\
\text { care }\end{array}$} & Quality of care & $\begin{array}{l}\text {-Provide pragmatic services in the form of psychological and } \\
\text { emotional support } \\
\text {-Provide adherence-to-treatment support } \\
\text {-Provide useful maternal health information } \\
\text {-Help in providing priority attention to HIV-positive women upon } \\
\text { recommendation at the facility }\end{array}$ \\
\hline & & Limitations in quality & $\begin{array}{l}\text { - Limitation in skills } \\
\text {-Lack of access to medical supplies and equipment }\end{array}$ \\
\hline & Efficiency & Efficiency & . Protection from domestic violence and abuse \\
\hline
\end{tabular}


Table 2 Summary of qualitative results (Continued)

\begin{tabular}{|c|c|c|c|}
\hline Respondent group & $\begin{array}{l}\text { Global } \\
\text { theme }\end{array}$ & Organizing theme & Basic findings from the FGDs and interviews \\
\hline & & & $\begin{array}{l}\text {-Provide useful information regarding maternal health promotion } \\
\text { and nutrition } \\
\text {-Provide transportation where possible to facilities } \\
\text {-Help in providing priority attention to HIV-positive women upon } \\
\text { recommendation at the facility }\end{array}$ \\
\hline & & $\begin{array}{l}\text { Limitations in } \\
\text { efficiency }\end{array}$ & $\cdot N / A$ \\
\hline & Affordability & Affordability & $\begin{array}{l}\text {-Cheap } \\
\text { - No fees required }\end{array}$ \\
\hline & & $\begin{array}{l}\text { Limitations in } \\
\text { affordability }\end{array}$ & $\cdot N / A$ \\
\hline & Access & Access & $\begin{array}{l}\text {-Readily available to communities } \\
\text {-Provide services to everyone including those who would have } \\
\text { otherwise been left unattended to }\end{array}$ \\
\hline & & & -They view their work as a civic duty to the community \\
\hline & & Limitations to access & $\cdot N / A$ \\
\hline & Policy & $\begin{array}{l}\text { Provide referral } \\
\text { services }\end{array}$ & $\begin{array}{l}\text {-Provide transportation where possible to facilities } \\
\text {-Help in providing priority attention to HIV-positive women upon } \\
\text { recommendation at the facility }\end{array}$ \\
\hline & & $\begin{array}{l}\text { Advantages of } \\
\text { government policy on } \\
\text { TBAs }\end{array}$ & $\cdot N / A$ \\
\hline & & $\begin{array}{l}\text { Limitations as a result } \\
\text { of government policy } \\
\text { on TBAs }\end{array}$ & $\begin{array}{l}\text { - Lack of support from government due to promotion of facility- } \\
\text { based policy creates cooperation problems with professionals } \\
\text { - Obscures training opportunities for TBAs } \\
\text { - In conflict with government policy }\end{array}$ \\
\hline \multirow[t]{8}{*}{$\begin{array}{l}\text { Professional's characterization of trained } \\
\text { TBAs }\end{array}$} & $\begin{array}{l}\text { Quality of } \\
\text { care }\end{array}$ & Quality of care & $\begin{array}{l}\text {-Can provide soft services, e.g., psychological and emotional support } \\
\text { including treatment adherence support } \\
\text {-Provision of referrals services }\end{array}$ \\
\hline & & Limitations in quality & $\begin{array}{l}\text {-As opposed to TBAs, professionals can conduct completed } \\
\text { procedures such as cesarean births } \\
\text {-As opposed to TBAs, professionals can effectively handle } \\
\text { complications } \\
\text {-Have access to life-serving medical equipment used to conduct } \\
\text { complicated operations }\end{array}$ \\
\hline & Affordability & Affordability & More affordable than institutions \\
\hline & & $\begin{array}{l}\text { Limitations in } \\
\text { affordability }\end{array}$ & $\cdot N / A$ \\
\hline & Efficiency & Efficiency & $\cdot N / A$ \\
\hline & & $\begin{array}{l}\text { Limitations in } \\
\text { efficiency }\end{array}$ & Inadequate funding to cooperation between TBAs and professionals \\
\hline & Policy & $\begin{array}{l}\text { Advantages of } \\
\text { government policy on } \\
\text { TBAs }\end{array}$ & $\cdot N / A$ \\
\hline & & $\begin{array}{l}\text { Limitations as a result } \\
\text { of government policy } \\
\text { on TBAs }\end{array}$ & $\begin{array}{l}\text { Policy frustrates cooperation between professionals and TBAs } \\
\text {-Counterproductive government policy on TBAs } \\
\text {-Creates barriers in accessing the most vulnerable women in remote } \\
\text { areas }\end{array}$ \\
\hline
\end{tabular}

\section{Participant 7}

Despite the largely positive characterization of their experiences with trained TBAs, some participants were cognizant of the fact that some complicated functions were not the preserve of trained TBAs, but rather of highly skilled medical practitioners. A clear demarcation of services between those of TBAs and those of highly skilled medical practitioners was visible in their responses:

"People like us (who are HIV positive) always need to constantly take medication (antiretroviral therapy) 
and have cesarean births and for such, I think doctors are more helpful"

\section{Participant 2}

\section{Women who have never accessed services of trained TBAs}

Although HIV-positive women who utilized skilled attendants also had varied responses, in general, most of them spoke highly of professional care. Considering the vulnerability that comes with being HIV positive, TBAs were considered to be a risky option by these women. Their argument centered on the idea that TBAs were not able to give accurate advice to women with HIV regarding specific complications that may arise during pregnancy. It is for this reason that they preferred professional care over trained TBAs. In as much as they praised professional care, these women remained critical of the logistical and economic difficulties involved in accessing professional care in health facilities.

"Imagine if I experience some difficulties of whatever kind, do you think the TBA will know exactly what is wrong with me? Let alone give proper advice? Being HIV positive means that on a daily basis you need professional advice but I am not sure if TBAs can do this."

\section{Participant 13}

"I also agree that going to facilities is really expensive and very difficult. I only managed because my partner owns a motor-bike, so imagine women without such options"

\section{Participant 14}

Although the majority of the women who gave birth in facilities praised facility-based care, some of them criticized professionals for exhibiting "bad attitude." These women stated that they were neglected and abused by medical practitioners in health facilities. Specifically, three of them accused professionals of verbally and physically abusing them during labor.

"I was left alone without any attention when my water broke. It was in the night and the nurses were busy elsewhere. They were not present.."

\section{Participant 16}

“. ..They shouted at me and sometimes slapped me for not doing what they wanted me to do. I understand that they work under very difficult conditions too, but I think this is the job they signed up for and as such, they are required to be nicer and give very good services to their patients...."

Participant 18

\section{Trained traditional birth attendants}

Trained TBAs stated how their functions were usually misunderstood and misrepresented by most people who usually accused them of duplicating medical professionals' roles. Trained TBAs categorically distinguished their services from professional care by highlighting that their functions were only to provide "soft services" (such as treatment adherence support, nutritional support, counseling, psychological support, logistical support, and referrals to facilities). Their functions did not, in any, way include surgical procedures. This, therefore, meant that their services were complementally and not substitutional to those of professional care givers in health facilities.

"This is where we come in. we use the Zambulance to transport these HIV positive women to the clinics for specialized treatment. So our services are very pragmatic. We have been able to provide a range of services that include care during pregnancy, help with adherence in treatment, including provision of nutritional needs where possible."

Participant 26.

"..We do not duplicate the work of doctors. We do not perform cesarean procedures, this is beyond us. Our services in women with HIV are straightforward"

Participant 28.

\section{Medical professionals}

Although medical professionals, in general, were critical of trained TBAs by suggesting that services of TBAs had some shortcomings (e.g., lacked adequate knowledge), some of them acknowledged the importance of TBAs in maternal care of women with HIV. Specifically, they highlighted how useful their functions (psychological, social, and logistical support) were especially in the face of inadequate health workers.

"..TBAs are the immediate help available to women here in Mfuwe. So in most cases they are the only readily available source of help. I think there should be a way Government taps into this and officially involve them in the process of maternal care. They do provide a lot of help to HIV positive women. Most of the women who come here to the clinic are usually transported by the Zambulance organized by local 
TBAs. They are still a very important part of the maternal care channel. Also, when we put our patients on treatment, it's TBAs in the villages who ensure that these patients adhere to treatment because we are not physically present...."

Participant 35.

\section{Discussion}

In this study, we set out to assess the varied ways our respondents characterized the relevance of trained TBAs in maternal care of women living with HIV in Zambia. Our findings illustrate the fact that despite the Zambian government's policy (which emphasizes strict utilization of professional care for women with HIV), women have continued to utilize services of trained TBAs [5, 15]. Specifically, TBAs provide the following "soft services" to women with HIV: treatment adherence support, nutritional support, counseling, psychological support, logistical support, and referrals to facilities. This means that these services form part of a pragmatic response to maternal health care in Zambia. As other scholars have pointed out $[3,16]$, maternal health care is a continuum which requires attention not only of medical professionals but also of TBAs (in the form of soft services) [7].

A growing body of literature [17] has consistently pointed out that most resource-poor settings can benefit from task shifting through apportioning and recognizing suitable functions of trained TBAs. In line with this, evidence from our study suggests that TBAs can help improve access to care, decongest health facilities, and counteract social barriers to antiretroviral treatment, all of which are important in promoting maternal health in women with HIV. Just as other studies have shown elsewhere [7, 9], we demonstrate that TBAs indeed do have limitations (such as lack of advanced knowledge); however, delegitimizing them because of this means that opportunities to maximize their benefits and minimize their costs are effectively lost. It thus seems clear that there is much to lose when TBAs are not recognized and regulated within the line of care, as this will effectively force them to operate without any form of regulation. It can be seen that despite government's efforts [6] to promote exclusive institutional care, HIV-positive women have continued to rely on trained TBAs due to structural barriers to professional care in Zambia. A policy of strict institutional care for women with HIV is out of touch with the realities of Zambia.

While popular recommendations (which involve increasing access to skilled care by training more health workers and constructing more hospitals) all seem attractive and useful to HIV-positive women, the reality is that poor governments have struggled to achieve these goals. Yet, despite all these constraints, TBAs remain a feasible (albeit less regarded) option to help lessen the burden of maternal care. Other studies from Malawi [18] and Zambia [16], for example, suggest that inclusion of TBAs in the line of care has the potential to reduce maternal mortality, neonatal deaths, and stillbirths. Our study comes to the same conclusion as other studies $[7,16,9,19,20]$ on task shifting, which is that in order to promote maternal health of women with HIV in Zambia, TBAs must officially be integrated in the existing health systems. It is clear from our study that because of the existing inefficient health system, local people characterize TBAs as useful stakeholders in improving maternal health of HIV-positive women. TBAs do not pose any threats to skilled midwives because the functions of the two in relation to maternal health of women with HIV are not mutually exclusive but complementary.

In this study, we note some potential limitations. Specifically, due to logistical and financial constraints, our findings are based only on the views of participants who were located in only one of the ten provinces of Zambia. Further, due to financial and logistical limitations again, our sample size was only composed of 40 participants. This fact may have limited the variety of experiences with trained TBAs in Zambia in general. However, we argue that our study from Zambia was adequate and relevant in giving insights into the relevance of TBAs in maternal care of HIV-positive women in rural settings.

\section{Conclusion}

Our study shows that despite government's efforts to promote exclusive professional care for women with HIV, women in Zambia continue to utilize trained TBAs. In Zambia, trained TBAs have consistently provided "soft services" which include treatment adherence support, nutritional support, counseling, psychological support, logistical support, and referrals to facilities. We have shown that maternal care is not a zero-sum game, but a continuum in which both trained TBAs and professionals each have complementary roles to play. In this regard, it seems profitable for the government of Zambia to systematically integrate trained TBAs in maternal care of HIV-positive women; doing this will ensure improved cooperation between different stakeholders, improved access, and quality of care. It will consequently make maternal care of HIV-positive women more efficient because integrated tasks can be allocated in a wellcoordinated and regulated manner.

\section{Abbreviations}

AIDS: Acquired immune deficiency syndrome; ART: Antiretroviral treatment; HIV: Human immunodeficiency virus; PMTCT: Prevention of mother to child transmission: SSA: Sub-Saharan Africa; TBA: Traditional birth attendants;

WHO: World Health Organization 


\section{Acknowledgements}

We like to acknowledge the CIRDZ team for their assistance in the collection of data.

\section{Funding}

The study was self-funded.

\section{Availability of data and materials}

The data generated and/or analyzed during the current study are not publicly available due to the fact that they contain people's private information including their HIV status but are available from the corresponding author on reasonable request.

\section{Authors' contributions}

All authors collaborated and contributed to the formulation of objectives of the study and oversaw the development of the study concept and design, data collection and analysis, including the drafting of the manuscript. All authors at every stage contributed in drafting, correcting, and perfecting the manuscript. CM was tasked with consolidating all the contributions to the manuscript and taking care of all correspondence. All authors read and approved the final manuscript.

\section{Ethics approval and consent to participate}

We obtained ethical clearance from the National Health Research Authority of Zambia and from the Zambian ERES Converge IRB. Other than that, informed consent was sought from the participants before participation and they were informed of their right to discontinue their participation at any point should they wish to.

\section{Consent for publication}

Consent to publish the results was granted by the National Research Authority of Zambia and respondents.

\section{Competing interests}

The authors declare that they have no competing interests.

\section{Publisher's Note}

Springer Nature remains neutral with regard to jurisdictional claims in published maps and institutional affiliations.

\section{Author details}

${ }^{1}$ Maastricht Graduate School of Governance/UNU-Merit, Maastricht University, Maastricht, the Netherlands. ${ }^{2}$ A9 Marshlands Village, P.O. Box 32379, Lusaka, Zambia. ${ }^{3}$ Department of Health Services Research, CAPHRI, Maastricht University Medical Center, Faculty of Health, Medicine and Life Sciences, Maastricht University, Maastricht, the Netherlands. ${ }^{4}$ Top Institute for Evidence-Based Education Research (TIER), Maastricht University, Maastricht, the Netherlands. ${ }^{5}$ Department of Economics, University of Liege, Liege, Belgium.

Received: 7 September 2017 Accepted: 25 October 2017

Published online: 13 November 2017

\section{References}

1. Crowe M, Utley A, Costello, Pagel C. How many births in sub-Saharan Africa and South Asia will not be attended by a skilled birth attendant between 2011 and 2015? BMC Pregnancy and Childbirth. 2012;12(4)

2. WHO, "World Health Statistics 2013," WHO, Geneva, 2013.

3. Mbiydzenyuy NE. Traditional birth attendants: filling the blank space. Yaunde: Maternal and Child Aid Cameroon; 2012.

4. Harrison K. Are traditional birth attendants good for improving maternal and perinatal health? No. Br Med J. 2011:342.

5. USAID. MCH program discription-Zambia. New York: USAID; 2008.

6. Family-Care-International, "Mapping maternal health advocacy-a case study of Zambia," Global Health insights, 2013.

7. Ana J. Are traditional birth attendants good for improving maternal and perinatal health? Yes. Br Med J. 2011:342.

8. Bergstrom S, Goodburn E. The role of traditional birth attendants in the reduction of maternal mortality. Safe motherhood strategies: a review of the evidence. 2001:451.
9. Choguya NZ. Traditional birth attendants and policy ambivalence in Zimbabwe. J Anthropol. 2014:

10. Kelly G, Mulgan G, Muers S. Creating public value: an analytical framework for public service reform. London: Strategy Unit, Cabinet Office; 2012.

11. Mahdon M. Public value and health. London: The Work Foundation project; 2006

12. Central-Statistical-Office. Zambia 2010 census of population and housing. Lusaka: CSO; 2010.

13. ZDH, "Zambia demographic health survey," United States Agency for International Development (USAID), Lusaka, 2013.

14. ZDH. Zambia demographic health survey. In: United States Agency for International Development (USAID), Lusaka; 2013.

15. Braun V, Clarke V. Using thematic analysis in psychology. Qualitative research in psycholog. 2006;3(2):77-101.

16. Ministry-of-Health. Roadmap for accelerating reduction of maternal, newborn and child mortality, 2013-2016. Lusaka: Ministry of Health; 2013.

17. Gill C, Phiri-Mazala G, Guerina N, J K, C M, MacLeod. Effect of training traditional birth attendants on neonatal mortality (Lufwanyama Neonatal Survival Project) randomised controlled study. BMJ. 2011:342-6.

18. Mwai GW, Mburu G, Torpey K, Frost P, Ford N, Seeley J. Role and outcomes of community health workers in HIV care in sub-Saharan Africa: a systematic review. J Int AIDS Soc. 2013;16:185-6.

19. C. Ngozo, "Malawi: uncertainty over role for traditional birth attendants," global issues, 2011.

20. Balogun M, Odeyemi K. Knowledge and practice of prevention of motherto-child transmission of HIV among traditional birth attendants in Lagos state, Nigeria. The Pan African Medical Journal. 2010;5(7)

\section{Submit your next manuscript to BioMed Central and we will help you at every step:}

- We accept pre-submission inquiries

- Our selector tool helps you to find the most relevant journal

- We provide round the clock customer support

- Convenient online submission

- Thorough peer review

- Inclusion in PubMed and all major indexing services

- Maximum visibility for your research

Submit your manuscript at www.biomedcentral.com/submit
Biomed Central 